\title{
Antenatal psychosocial assessment for reducing perinatal mental health morbidity (Review)
}

Austin MP, Priest SR, Sullivan EA
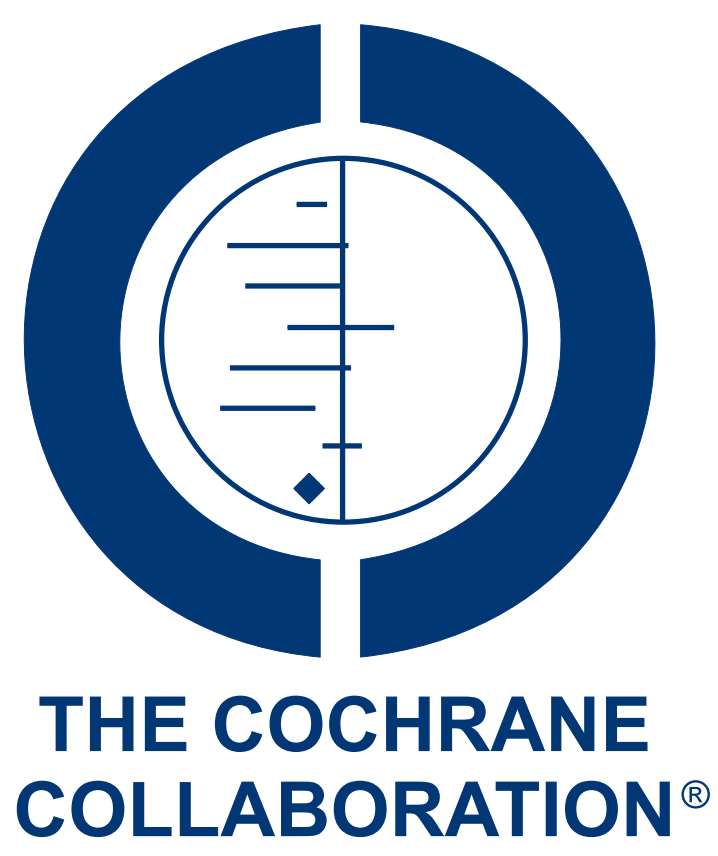

This is a reprint of a Cochrane review, prepared and maintained by The Cochrane Collaboration and published in The Cochrane Library 2009, Issue 1

http://www.thecochranelibrary.com

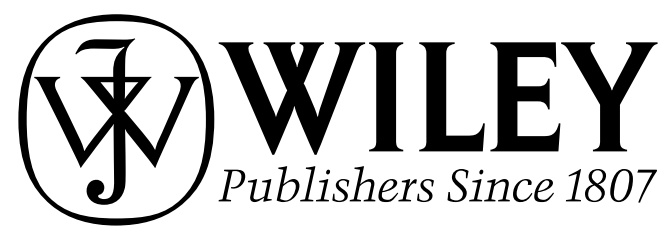

Antenatal psychosocial assessment for reducing perinatal mental health morbidity (Review)

Copyright $\odot 2009$ The Cochrane Collaboration. Published by John Wiley \& Sons, Ltd. 


\section{TABLE OF CONTENTS}

ABSTRACT

PLAIN LANGUAGE SUMMARY . . . . . . . . . . . . . . . . . . . . . . . . . . . . . . . . . . .

BACKGROUND . . . . . . . . . . . . . . . . . . . . . . . . . . . . . . . . . . . . . . 3

OBJECTIVES . . . . . . . . . . . . . . . . . . . . . . . . . . . . . . . . . . . . . 5

METHODS . . . . . . . . . . . . . . . . . . . . . . . . . . . . . . . . . . . . . . 5

RESULTS . . . . . . . . . . . . . . . . . . . . . . . . . . . . . . . . . . . . . . .

DISCUSSION . . . . . . . . . . . . . . . . . . . . . . . . . . . . . . . . . . . . . 9

AUTHORS' CONCLUSIONS . . . . . . . . . . . . . . . . . . . . . . . . . . . . . . . . 10

ACKNOWLEDGEMENTS . . . . . . . . . . . . . . . . . . . . . . . . . . . . . . . . . . . . 10

REFERENCES . . . . . . . . . . . . . . . . . . . . . . . . . . . . . . . . . . . . . . 11

CHARACTERISTICS OF STUDIES . . . . . . . . . . . . . . . . . . . . . . . . . . . . . . 14

DATA AND ANALYSES . . . . . . . . . . . . . . . . . . . . . . . . . . . . . . . . . . . . . . . . . . . . . . . . . 18

Analysis 1.1. Comparison 1 IDEA versus standard care, Outcome 1 EPDS $>12$ (at 16 weeks postpartum). . . . . . 18

Analysis 2.1. Comparison 2 ALPHA versus standard care, Outcome 1 High level of provider concern (adj for cluster). 19

Analysis 2.2. Comparison 2 ALPHA versus standard care, Outcome 2 At least one psychosocial concern identified (adj for cluster). . . . . . . . . . . . . . . . . . . . . . . . . . . . . . . . . . . . . . . .

Analysis 2.3. Comparison 2 ALPHA versus standard care, Outcome 3 At least one concern identified in at least one woman (by provider). . . . . . . . . . . . . . . . . . . . . . . . . . . . . . . . . . . . . . . 20

Analysis 2.4. Comparison 2 ALPHA versus standard care, Outcome 4 Women identified with a risk factor (adj for cluster). . . . . . . . . . . . . . . . . . . . . . . . . . . . . . . . . . . . . . . . . . . . . . 20

Analysis 2.5. Comparison 2 ALPHA versus standard care, Outcome 5 Failure to identify EPDS $>9$ antenatally. $\quad . \quad$. 21

WHAT'S NEW . . . . . . . . . . . . . . . . . . . . . . . . . . . . . . . . . 21

HISTORY . . . . . . . . . . . . . . . . . . . . . . . . . . . . . . . . . . . . . . . . 21

CONTRIBUTIONS OF AUTHORS . . . . . . . . . . . . . . . . . . . . . . . . . . . . . . . . . . . . 21

DECLARATIONS OF INTEREST . . . . . . . . . . . . . . . . . . . . . . . . . . . . . . . . . . 21

SOURCES OF SUPPORT . . . . . . . . . . . . . . . . . . . . . . . . . . . . . . . . . . . . . . . . . . . . . . . .

DIFFERENCES BETWEEN PROTOCOL AND REVIEW . . . . . . . . . . . . . . . . . . . . . . . . . . . . 22 
[Intervention Review]

\title{
Antenatal psychosocial assessment for reducing perinatal mental health morbidity
}

\author{
Marie-Paule Austin ${ }^{1}$, Susan R Priest ${ }^{2}$, Elizabeth A Sullivan ${ }^{3}$ \\ ${ }^{1}$ Black Dog Institute/School of Psychiatry, University of New South Wales, Sydney, Australia. ${ }^{2}$ (a) School of Public Health and \\ Community Medicine, University of New South Wales, Sydney, (b) Perinatal and Infant Psychiatry Program, University of Newcastle, \\ Wallsend, Australia. ${ }^{3}$ Faculty of Medicine, University of New South Wales, Randwick, Australia
}

Contact address: Marie-Paule Austin, Black Dog Institute/School of Psychiatry, University of New South Wales, Hospital Road, Sydney, New South Wales, 2052, Australia. m.austin@unsw.edu.au. (Editorial group: Cochrane Pregnancy and Childbirth Group.)

Cochrane Database of Systematic Reviews, Issue 1, 2009 (Status in this issue: Unchanged)

Copyright (C) 2009 The Cochrane Collaboration. Published by John Wiley \& Sons, Ltd.

DOI: $10.1002 / 14651858 . C D 005124 . p u b 2$

This version first published online: 8 October 2008 in Issue 4, 2008.

Last assessed as up-to-date: 6 June 2008. (Help document - Dates and Statuses explained)

This record should be cited as: Austin MP, Priest SR, Sullivan EA. Antenatal psychosocial assessment for reducing perinatal mental health morbidity. Cochrane Database of Systematic Reviews 2008, Issue 4. Art. No.: CD005124. DOI: 10.1002/14651858.CD005124.pub2.

\section{A B S T R A C T}

\section{Background}

Mental health conditions arising in the perinatal period, including depression, have the potential to impact negatively on not only the woman but also her partner, infant, and family. The capacity for routine, universal antenatal psychosocial assessment, and thus the potential for reduction of morbidity, is very significant.

\section{Objectives}

To evaluate the impact of antenatal psychosocial assessment on perinatal mental health morbidity.

\section{Search strategy}

We searched the Cochrane Pregnancy and Childbirth Group's Trials Register, the Cochrane Depression, Anxiety and Neurosis Group's Trials Register (CCDAN TR-Studies), HSRProj in the National Library of Medicine (USA), and the Current Controlled Trials website: http://www.controlled trials.com/ and the UK National Research Register (last searched March 2008).

\section{Selection criteria}

Randomised and quasi-randomised controlled trials.

\section{Data collection and analysis}

At least two review authors independently assessed trials for eligibility; they also extracted data from included trials and assessed the trials for potential bias.

\section{Main results}

Two trials met criteria for an RCT of antenatal psychosocial assessment. One trial examined the impact of an antenatal tool (ALPHA) on clinician awareness of psychosocial risk, and the capacity of the antenatal ALPHA to predict women with elevated postnatal Edinburgh Depression Scale (EDS) scores, finding a trend towards increased clinician awareness of 'high level' psychosocial risk where the ALPHA intervention had been used (relative risk (RR) $4.6195 \%$ confidence interval (CI) 0.99 to 21.39). No differences between groups

Antenatal psychosocial assessment for reducing perinatal mental health morbidity (Review)

Copyright ( 2009 The Cochrane Collaboration. Published by John Wiley \& Sons, Ltd. 
were seen for numbers of women with antenatal EDS scores, a score of greater than 9 being identified by ALPHA as of concern for depression (RR $0.6995 \%$ CI 0.35 to 1.38); 139 providers. The other trial reported no differences in EPS scores greater than 12 at 16 weeks postpartum between the intervention (communication about the EDS scores with the woman and her healthcare providers plus a patient information booklet) and the standard care groups (RR $0.8695 \%$ CI 0.61 to 1.21 ; 371 women).

\section{Authors' conclusions}

While the use of an antenatal psychosocial assessment may increase the clinician's awareness of psychosocial risk, neither of these small studies provides sufficient evidence that routine antenatal psychosocial assessment by itself leads to improved perinatal mental health outcomes. Further studies with better sample size and statistical power are required to further explore this important public health issue. It will also be important to examine outcomes up to one year postpartum not only for mother, but also infant and family.

\section{PLAIN LANGUAGE SUMMARY}

\section{Antenatal psychosocial assessment for reducing perinatal mental health morbidity}

Women can develop mental health problems during pregnancy or at childbirth and over the following year. These problems range from depression (both minor and major), anxiety disorders, post-traumatic stress disorder to bipolar disorder, schizophrenia and psychosis (puerperal psychosis). Life stresses such as bereavement, separation, unemployment, illness, moving house, migration, lack of social support networks, a past history of psychological or psychiatric disorders, history of physical, emotional or sexual abuse, drug or alcohol abuse, dysfunctional personality or coping styles and parenting behaviours can contribute to their onset. Obstetric factors such as timing and type of delivery and infant temperament can also play a role. Disorders may become chronic and carry over to future pregnancies. The mother's mood during pregnancy and mental illness can impact on the development of the baby both during pregnancy and after birth. Assessing women for psychosocial risk factors and symptoms of distress during regular pregnancy checks gives the opportunity to link women with appropriate services.

The one study that met the criteria for this review randomised healthcare providers to either psychosocial assessment or routine care and involved a total of 273 women. The providers who assessed psychosocial factors were more likely than those giving routine care to identify psychosocial concerns and to rate the level of concern as high. They were also more likely to detect concerns about family violence. The trial did not look at the development of anxiety or depression in these women. Not all healthcare providers chose to take part in the trial and some dropped out, leaving only 48 of the original 185 approached. This could mean that providers who were less interested in this area of clinical practice did not participate and bias the findings toward better than average detection of psychosocial risk. Two studies are currently in progress looking at the impact of early postnatal psychosocial assessment on the prevalence of antenatal and postnatal anxiety and depression. 


\section{B A C K G R O U N D}

\section{Description of the condition}

Perinatal mental health problems associated with pregnancy, childbirth, and the first postnatal year are recognised as a major public health issue, with as many as $15 \%$ of childbearing women likely to develop a new episode of major or minor depression in the interval between conception and the first three postpartum months ( Gavin 2005). Disorders arising in the perinatal period include minor and major depression, anxiety disorders, post-traumatic stress disorder, bipolar disorder, schizophrenia, and puerperal psychoses (Brockington 2004; Elliot 2000; Fergusson 1996; Johanson 2000; O'Hara 1997; Stuart 1998). Comorbid disorders are common in this population (Carter 2003; Preisig 2001) and mental illness is often complicated by issues of drug and alcohol abuse and domestic violence (Bacchus 2004; Carter 2003; Doggett 2005). Maternal mental health and drug dependence issues are among the leading causes of maternal death in the perinatal period (Austin 2007; Oates 2003).

The extent of perinatal mental health problems in developing countries is largely unknown, though small-scale studies of postnatal depression prevalence carried out amongst women in developing nations, based mainly on self-report measures of maternal distress, have reported rates ranging from $32 \%$ in India to $61 \%$ in Taiwan (Patel 2004). For some women there is a continuum of depressive symptoms from pregnancy into the postnatal period and in some cases disorders become chronic and persist through more than one pregnancy (Austin 2003a). Between 20\% and 40\% of women with a previous history of postnatal depression are likely to suffer a relapse after birth (Cooper 1995). Anxiety symptoms are also common during pregnancy and the postpartum year, either in association with depressive symptoms or in the context of discrete anxiety spectrum disorders (Austin 2003a; Matthey 2004), though there have been few epidemiological studies (Glover 2002; Heron 2004). The need to assess men and women during the postnatal period for symptoms of anxiety as well as depression has been suggested (Matthey 2003).

Maternal mental illness can also have an adverse impact on the cognitive, emotional, social, and behavioural development of infants (Atkinson 1997; Barnett 1993; Campbell 1995; Civic 1993; Murray 1997; Murray 2004; O’Connor 2002). Significant associations have also been found between maternal postnatal depression and adverse physical health outcomes in infants and young children (Patel 2004). Parental relationships are often disrupted when one partner suffers from a mental illness, and some mothers are required to assume the role of primary caregiver for infants and young children while battling with mental illness (Murray 2003; Murray 2004). Effects on the mother-infant bond have been shown to persist after resolution of the maternal mood disorder, which has led to speculation that it may be 'sub-optimal' parenting behaviours that are the mediating variable rather than the psychiatric disorder per se (Austin 2003a; Cooper 2003). The presence of social support and partner support have been shown to have a moderating influence on maternal depression and upon infant outcomes (Boyce 1994; Matthey 2003; Misri 2000). Recent research findings indicate that antenatal maternal mood state impacts upon in utero development of the infant, with significant associations found between levels of maternal distress during pregnancy and child behavioural outcomes (O'Connor 2002). The possible mechanism for such associations is thought to be the hypothalamic pituitary adrenal axis which has a complex regulatory role in relation to endocrine functions (Austin 2000; Glover 2002; Huizink 2002)

\section{Issues around terminology}

Recently, the UK National Institute for Health and Clinical Excellence (NICE) released clinical management and service guidance for Antenatal and Postnatal Mental Health (APMH) conditions ( NICE 2007). They define 'screening' as fulfilling two functions: prediction and detection. They go on to define prediction as "the identification of risk factors, current or past, which increase the probability of onset of a mental health disorder, or of relapse of a previous mental health disorder at some point in the future." Detection is used to refer to "the identification of a current disorder." These definitions help to conceptually expand our understanding of the term 'screening' as it has been applied to this literature.

In this review, rather than using the term 'screening', we have used the term 'assessment', which refers to the broad psychosocial evaluation of the client, including risk factors and current symptoms which may be enhanced by the use of relevant measures. Thus, in the context of perinatal mental health, screening can only be legitimately applied to well-established quantifiable scales, such as the Edinburgh Postnatal Depression Scale (EPDS; Cox 1987), which is also known as the Edinburgh Depression Scale (EDS) when used antenatally (Murray 1990). We have thus considered all studies examining psychosocial assessment in pregnancy, including the subset that look specifically at the impact of 'screening' for perinatal depression. For the sake of simplicity, we shall henceforth use the term EDS to refer to the Edinburgh Depression Scale, whether used antenatally or postnatally.

\section{Description of the intervention}

Antenatal psychosocial assessment - the intervention being assessed in this review - is a public health policy initiative. It is set within a primary prevention framework that is being trialed in many centres in conjunction with prevention, early intervention, and treatment programs with the objective of reducing perinatal mental health morbidity and mortality rates (Austin 2003a). The procedures are designed to identify symptoms of maternal distress and the presence of psychosocial risk factors for the full spectrum of clinical disorders. They are not intended to predict specific clinical disorders, nor to take the place of formal assessment leading to a clinical diagnosis. Universal psychosocial assessment is a rela- 
tively new and still controversial undertaking within the maternity setting, as outcome studies have not yet emerged in support of any single agreed tool or method for identifying those women most at risk of mental health problems.

The Antenatal Psychosocial Health Assessment (ALPHA) (Carroll 2005) incorporates 15 risk factors found to be associated with woman abuse, child abuse, postpartum depression, and couple dysfunction. These risk factors are grouped with suggested questions into four categories: family factors, maternal factors, substance use, and family violence. The Antenatal Risk Questionnaire (ANQR) (Austin 2003b) and its longer validated precursor the Pregnancy Risk Questionnaire (Austin 2005) are examples of self-report psychosocial assessment tools allowing derivation of a score which aids in the referral decision making process. Another psychosocial risk questionnaire, not dissimilar to the ANRQ, is administered by the midwife and also used in the context of comprehensive pathways to care for high-risk women and families ( Barnett 2005). These tools (Austin 2003b; Austin 2005; Barnett 2005) are designed to be used in association with the EDS and clinical interview, and the ANRQ (Austin 2003b) has defined criteria for assessment of 'high', 'medium' or 'low' psychosocial risk status. These tools have been field-tested and found to be useful to staff and acceptable to clients. Indeed, pregnant women appreciate and feel comfortable with these psychosocial assessments ( Buist 2006).

\section{Methodological issues around the intervention}

Unlike cancer screening where, for example in breast and cervical cancer, there are recognised screening tests with high sensitivity, specificity and positive predictive value (PPV), no tools with comparable credentials exist for the early detection of anxiety or depression. Clearly the issue of identifying early depression when screening is based on the use of self-report questionnaires would be expected to present more challenges than the detection of an early pathological lesion. Yet even within the cancer screening context, there has been significant controversy about the utility of routine screening as assessed by randomised controlled trials (RCTs) ( Mietinnen 2003). Thus, the benefit of screening for breast cancer with mammography has proven to be unresolved (Gotzsche 2006). Furthermore, with respect to routine cervical screening (which has been standard practice for many years), there have so far been no RCTs undertaken to evaluate its efficacy (Mietinnen 2003).

There are added complexities when attempting to screen in the mental health setting, including the nonspecificity of psychological symptoms that may turn out to be associated with different clinical disorders, or the fact that emerging symptoms may not progress or remain constant over time. These factors are all likely to contribute to the low PPVs reported in studies examining screening for depression in the perinatal mental health context (Austin 2003a).

The majority of clinical and research investigations into perinatal disorders have been concerned with postnatal depression, as identified by elevated scores on the EDS. The EDS, a self-report questionnaire enquiring about symptoms of depression and anxiety in the preceding week, does not provide a diagnosis of depression, although elevated scores have been used as indicative of postnatal depression in some studies. Recent Australian research (Priest 2003) found that one in five women who delivered fullterm infants in a major obstetric hospital in Australia either had a current clinical disorder at the time of delivery or met psychiatric diagnostic criteria based on the Diagnostic and Statistical Manual of Mental Disorders, 4th edition (DSM-IV) (APA 1994) for a range of perinatal mental health problem within the first year after birth.

Research into risk factors for antenatal and postnatal anxiety has been quite limited but shows overlap with those identified for postnatal depression (Matthey 2004). Improved rates of prediction of postnatal depression following classification of women during pregnancy in to high-risk and low-risk groups on the basis of antenatal assessment for presence of psychosocial risk factors for depression have been reported (Austin 2005a; Verkerk 2003). However the choice of risk factors that should be used in a clinical interview to identify women at risk of mental health difficulties in the perinatal period remains somewhat debatable as outlined in Antenatal and Postnatal Mental Health: The NICE Guideline on Clinical Management and Service Guidance (NICE 2007). Very little is known about rates of 'false positive' and 'false negative' outcomes following psychosocial assessment, and there is also very limited detailed information available about patterns of uptake of referrals to mental health services and utilisation of specialised programs by women identified as being 'at risk' during pregnancy (Lumley 2004).

\section{How the intervention might work}

Psychosocial assessment programs in perinatal settings are designed to identify women who show early symptoms of distress, and/or have psychosocial risk factors known to be associated with clinical onset of mental health problems. The objective is for these women, once identified, to be linked with appropriate services. Earlier programs only screened for postnatal depression. However, recognition that many risk factors and symptoms of mental illness can be detected during pregnancy (Cox 1993; Oates 2003; O'Hara 2004) prompted calls for antenatal psychosocial assessment to be introduced into obstetric hospitals and outpatient clinics and carried out routinely when women attend for pregnancy checks (Austin 2005a; Buist 2002; Shakespeare 2001). Psychosocial assessment programs are primarily structured to detect symptoms and/or risk factors for high-prevalence anxiety disorders and depression that often go undetected or unreported (Murray 2003), rather than low-prevalence but usually more visible disorders such as puerperal psychosis (Austin 2005; Buist 2002). However a previous history of these disorders, and thus the risk of relapse, should be enquired about. 
The hypothesis that antenatal psychosocial assessment programs used in conjunction with early intervention and treatment strategies contribute to reduced mental health morbidity and mortality remains to be proven in large-scale outcome studies, and there is ongoing debate about the measures and procedures (Austin 2003c; Buist 2002; Matthey 2004; Shakespeare 2001). Concerns have been expressed about the shortages of programs and services in some areas to follow up women who are identified as high risk, leading to recommendations that screening not be introduced in such settings (NSC 1998; NSC 2003). Cautions have been expressed about use of the EDS during pregnancy and the current lack of screening instruments that meet minimum criteria for routine antenatal use including safety, simplicity, precision and adequate validation (Austin 2003c). Despite the fact that antenatal psychosocial assessment clearly requires considerable additional evaluation as a preventive and early intervention strategy, it continues to be implemented pending validation and longer-term outcome studies.

A number of Cochrane reviews have addressed the issues around assessment and treatment of postnatal depression including psychological, psychosocial and pharmacological interventions (Barlow 2003; Dennis 2004; Dennis 1999; Hoffbrand 2001). None of these publications is concerned primarily with the measures and methods for antenatal psychosocial assessment amongst pregnant women which is the focus of this review. A review of controlled trials of antidepressant treatment for postnatal depression (Hoffbrand 2001) included one study (Appleby 1997) showing that treatment with fluoxetine compared favourably with placebo and with a course of cognitive-behavioural counselling. Use of antidepressants in prevention of postnatal depression is considered in Howard 2005. A recent review that evaluated the preventive and treatment value of oestrogens and progestogens in relation to postnatal depression found little evidence to support these practices (Dennis 1999). On the psycho-educational front, a groupbased parent-training program for teenage parents showed some positive postnatal effects upon maternal mood, self-esteem and marital adjustment (Barlow 2003). One recent Cochrane review (Dennis 2004) evaluates antenatal and postnatal 'preventive psychosocial interventions' designed to prevent postnatal depression, but does not focus on antenatal psychosocial assessment as an intervention.

Other comprehensive systematic reviews have evaluated antenatal and/or postnatal therapist-led psychological interventions for postnatal depression, also without any consideration of the role played by antenatal psychosocial assessment (Austin 2003c; Lumley 2004; Matthey 2004; Ogrodniczuk 2003). A comprehensive systematic review (Austin 2003a) assessing the capacity of antenatal psychosocial screening to predict postnatal depression reported that none of the tools developed up to that time met the criteria for routine application in the antenatal period; in particular none of the tools had adequate sensitivity or positive predictive values. However this paper did not review the evaluation of psychosocial assessment by means of randomised controlled trials, nor of its value as an intervention independent of therapist-led psychological interventions.

\section{O B J E C T I VES}

\section{Primary aims}

To evaluate the effects of antenatal psychosocial assessment (compared to routine antenatal care) on mental health morbidity of women during pregnancy and the first postnatal year.

\section{Secondary aims}

1. To assess any adverse maternal outcomes associated with antenatal psychosocial assessment.

2. To provide a brief review of the screening properties of the major antenatal psychosocial assessment tools developed to date.

\section{METHODS}

\section{Criteria for considering studies for this review}

\section{Types of studies}

Studies can be published or unpublished and need to be randomised or quasi-randomised controlled trials of antenatal psychosocial assessment (including depression screening).

\section{Types of participants}

The focus is on pregnant women who have been assigned to either antenatal psychosocial assessment or standard care, and then followed up within one year after birth. Studies of healthcare providers who have been randomly assigned to provision of psychosocial assessment or standard care may also be included.

\section{Types of interventions}

The focus of the review is upon the primary 'intervention', namely the antenatal psychosocial assessment tools and methods of application. Tools can include symptom-based self-report measures such as the Edinburgh Postnatal Depression Scale or EDS used antenatally in these studies (Cox 1987); the Beck Depression Inventory (Beck 1961); Spielberger State-Trait Anxiety Scale ( Spielberger 1970); Centre for Epidemiological Studies Depression Scale (Radloff 1977); and Profile of Mood States (McNair 1971). Risk-based assessment measures and systems include the ALPHA (Carroll 2005), the Antenatal Risk Questionnaire (Austin 2003b), and the Pregnancy Risk Questionnaire (Austin 2005a).

\section{Types of outcome measures}




\section{Maternal outcomes}

1. Antenatal and/or postpartum psychological or psychiatric symptomatology assessed on structured psychiatric interviews that use standardised diagnostic criteria such as Diagnostic and Statistical Manual of Mental Disorders, 4th edition (DSM-IV) (APA 1994), Research Diagnostic Criteria (Endicott 1978), Diagnostic Interview Schedule (Robins 1981) and the Mini International Neuropsychiatric Interview (Sheehan 1998).

2. Scores on self-report measures of anxiety and/or depression such as the Edinburgh Postnatal Depression Scale and Spielberger State-Trait Anxiety Scale.

3. Health service utilisation, including outpatient and inpatient use of a psychiatric unit, or other mental health or psychosocial support services.

4. Use of anxiolytic or antidepressant medication or electroconvulsive therapy.

5. Clinical diagnosis of antenatal or postnatal anxiety and/or depression.

6. Treatment for antenatal or postnatal anxiety and/or depression.

7. Maternal-infant relationships variables.

8. Maternal ability to function in the home, at work, and in social contexts.

9. Women's views about the acceptability of the screening and intervention processes.

10. Maternal quality of life assessments.

11. Maternal satisfaction with care.

\section{Infant outcomes}

1. Initiation and duration of breastfeeding.

2. Infant health parameters including birthweight, weight gain patterns (e.g. failure to thrive), immunisation status, accidental injury, non-accidental injury, medical treatment.

3. Infant developmental assessments (cognitive, emotional, social or behavioural, as defined in trials).

4. Neurodevelopment at childhood follow up.

\section{Family outcomes}

1. Satisfaction with dyadic relationship.

2. Parental separation/divorce.

3. Family relationships and supports.

4. Family violence.

\section{Search methods for identification of studies}

\section{Electronic searches}

We searched the Cochrane Pregnancy and Childbirth Group's Trials Register by contacting the Trials Search Co-ordinator (March 2008).
The Cochrane Pregnancy and Childbirth Group's Trials Register is maintained by the Trials Search Co-ordinator and contains trials identified from:

1. quarterly searches of the Cochrane Central Register of Controlled Trials (CENTRAL);

2. weekly searches of MEDLINE;

3. handsearches of 30 journals and the proceedings of major conferences;

4. weekly current awareness alerts for a further 44 journals plus monthly BioMed Central email alerts.

Details of the search strategies for CENTRAL and MEDLINE, the list of handsearched journals and conference proceedings, and the list of journals reviewed via the current awareness service can be found in the 'Specialized Register' section within the editorial information about the CochranePregnancyandChildbirthGroup. Trials identified through the searching activities described above are each assigned to a review topic (or topics). The Trials Search Co-ordinator searches the register for each review using the topic list rather than keywords.

In addition, we searched to March 2008:

- The Cochrane Depression, Anxiety and Neurosis Group's Trials Register (CCDAN TR-Studies)

- HSRProj in the National Library of Medicine (USA)

- Current Controlled Trials web site: http://www.controlled trials.com

- UK National Research Register

- International Journal of Technology Assessment in Health Care

\section{Keywords}

For searching the additional databases, we used the following keywords:

antenatal, prenatal, pregnancy, perinatal, postnatal, postpartum, anxiety, depression, mood disorders, psychological screening, psychosocial risk factors, prevention, early intervention, treatment.

\section{Conference proceedings}

Marce Society, International (1980 to March 2008);

Marce Society, Australasian (1995 to March 2008).

\section{Searching other resources}

\section{Handsearches}

Reference lists for all identified and included studies; books, book chapters, and their bibliographies.

\section{Personal communication}

Authors of trials and published works, experts in the field identified through citations.

\section{Languages}

We did not apply any language restrictions.

\section{Data collection and analysis}

\section{Selection of studies}


Two review authors independently assessed potential studies for inclusion. We resolved disagreements through discussion.

\section{Data extraction and management}

We designed a form to extract data. At least two review authors extracted the data using the agreed form. We resolved discrepancies through discussion. Data were entered into Review Manager software (RevMan 2008) and checked for accuracy.

\section{Assessment of risk of bias in included studies}

Two review authors independently assessed risk of bias for each study using the criteria outlined in the Cochrane Handbook for Systematic Reviews of Interventions (Higgins 2008).

\section{(I) Sequence generation (checking for possible selection} bias)

For each included study, we described the methods used to generate the allocation sequence in sufficient detail to allow an assessment of whether it should produce comparable groups.

We assessed the methods as:

- adequate (e.g. random number table; computer random number generator; tossing a coin, minimisation);

- inadequate (odd or even date of birth; hospital or clinic record number); or

- unclear.

\section{(2) Allocation concealment (checking for possible selection} bias)

For each included study, we described the method used to conceal the allocation sequence in sufficient detail and determined whether intervention allocation could have been foreseen in advance of, or during, recruitment.

We assessed the methods as:

- adequate (e.g. telephone or central randomisation; consecutively numbered sealed opaque envelopes);

- inadequate (open random allocation; unsealed or nonopaque envelopes, alternation; date of birth);

- unclear.

\section{(3) Blinding (checking for possible performance bias)}

For each included study, we described all the methods used, if any, to blind study participants and personnel from knowledge of which intervention a participant received. Where blinding was not possible, we assessed whether the lack of blinding was likely to have introduced bias.

We assessed the methods as:

- adequate, inadequate or unclear for participants;

- adequate, inadequate or unclear for personnel;

- adequate, inadequate or unclear for outcome assessors

where 'adequate' is when there was blinding or where we assess that the outcome or the outcome measurement is not likely to have been influenced by lack of blinding.
(4) Incomplete outcome data (checking for possible attrition bias through withdrawals, dropouts, protocol deviations)

For each included study, we described the completeness of outcome data for each main outcome, including attrition and exclusions from the analysis. We stated whether attrition and exclusions were reported, the numbers (compared with the total randomised participants), reasons for attrition/exclusion where reported, and any re-inclusions in analyses which we undertook.

We assessed the methods as:

- adequate (e.g. where there were no missing data or where reasons for missing data are balanced across groups);

- inadequate (e.g. where missing data are likely to be related to outcomes or are not balanced across groups);

- unclear (e.g. where there is insufficient reporting of attrition or exclusions to permit a judgement to be made).

\section{(5) Other sources of bias}

For each included study, we described any important concerns we had about other possible sources of bias.

\section{Data synthesis}

We categorised trials according to key differences; for example, assessment methods used (symptom based/risk based); timing of assessment; method used to diagnose anxiety/depression (rating scales, interviews, self-report questionnaires); timing of follow up.

\section{Measures of treatment effect}

We carried out statistical analysis using the Review Manager software (RevMan 2008).

\section{Dichotomous data}

For dichotomous data, we presented results as summary relative risk with 95\% confidence intervals (converting from odds ratios where necessary); hence the significance of the results reported in this review using RR and adjusting where necessary for clustering may have been different to those reported in the original study.

\section{Continuous data}

For continuous data, we used the weighted mean difference if outcomes were measured in the same way between trials.

\section{Assessment of heterogeneity}

We would have used the $\mathrm{I}^{2}$ statistic to test for heterogeneity between trials.

\section{Data synthesis}

We planned to synthesise data separately for studies with a low risk of bias and those with a high risk of bias to explore the impact of possible bias on review findings.

\section{Subgroup analyses}

We planned subgroup analyses of types of screening (symptom based, risk based, combined); women grouped by risk status classification e.g. 'high' versus 'low' risk; women grouped by timing of onset of disorders--antenatal diagnoses versus postnatal; and differences between women diagnosed with anxiety versus depression 
versus mixed diagnosis (depression with anxiety). However there were insufficient data to perform any of these subgroup analyses.

\section{R E S U L T S}

\section{Description of studies}

See: Characteristics of included studies; Characteristics of excluded studies.

Two studies (Carroll 2005; Webster 2003a) fulfilled criteria for inclusion in this review (see Characteristics of included studies). We excluded a total of 22 studies. We excluded 17 cohort studies examining the sensitivity, specificity and positive predictive value of a variety of screening tools for the antenatal prediction of postnatal depression because they were not RCTs (see Characteristics of excluded studies). We excluded a further five studies (Austin 2008; Brugha 2000; Stamp 1996; Webster 2003b; Zlotnick 2001) because they undertook antenatal psychosocial assessments on all their participants before randomising them to antenatal psychosocial interventions or routine care and then assessing the impact of the intervention on rates of postnatal depression.

\section{Included studies}

Webster 2003a - reported a randomised controlled trial of 600 women identified as at significant risk (on the basis of a set of psychosocial risk items) before being allocated antenatally to either: (1) the "intervention", consisting of an Edinburgh Depression Scale and a discussion of their likely risk of postnatal depression based on their EDS score; (2) an information booklet about postnatal depression and available local resources, and a letter sent back to the referring GP and Child Health Nurse, advising of their likely risk of postnatal depression; or (3) "standard care", including midwifery case management and referral to social work or psychiatry as required. Follow up was at four months postpartum by means of the EDS.

Carroll 2005 - The primary focus of this study was on healthcare providers, i.e. comparing their awareness of psychosocial issues in pregnant women after administering the antenatal ALPHA (intervention) to the control providers. Carroll 2005 reported on a cluster RCT of 60 providers comparing the presence of psychosocial risk factors in the early postnatal period in two groups of women: those with an antenatal health care provider administering an antenatal psychosocial health assessment - the ALPHA - and those receiving "usual care". In a secondary analysis of the Carroll study, Blackmore 2006 examined the impact of the use of the ALPHA in pregnancy on clinician identification of probable antenatal and postnatal (six weeks) depression (as assessed independently by the research nurse). The antenatal EDS scores were not available to the healthcare providers, who had to indicate probable depression on the basis of the ALPHA alone. The ALPHA questionnaire does not generate a score, but was designed to alert non-mental health trained clinicians to a broad range of psychosocial risk factors in their patients.

\section{Risk of bias in included studies}

1) The Webster 2003a study identified potential study participants on the basis of their responding in the affirmative to any of the following risk factors: low support; past history of mental illness; family psychiatric illness; past postnatal depression; or having a mother with the same history. Of 2199 women assessed for eligibility at a large maternity hospital in an eight-month period, the majority were excluded because they were not positive on any risk factor, while a further 120 women were either not eligible (greater than 36 weeks pregnant or poor command of English), refused consent or were missed. This left 600 women who were randomised using a computer-generated list of random numbers and opaque, sequentially numbered envelopes.

Of those allocated to the intervention condition, 75/299 (25\%) women failed to receive all three components, leaving 224 in the intervention to receive follow-up. Incompleteness of intervention manifested predominantly as a failure to communicate risk status back to the GP. Of those allocated to the control condition, 6/301 women were mistakenly provided with a postnatal depression information booklet. Thus a total of 509 of the original 600 women were sent the EDS at four months postpartum. Comparable numbers of women were referred on: 60 women $(20 \%)$ in the control condition and $84(28 \%)$ in the intervention condition were referred to either a psychiatrist or social worker.

A total of $371 / 509$ (72.9\%) women returned their postpartum EDS; thus $27.1 \%$ women were lost to follow up. Loss to follow up was caused by failure to return postnatal EDS questionnaires, miscarriage or delivering out of area. This left 192 women in the intervention sample and 179 in the control sample. The rate of dropout was further increased to $38 \%$ if we include those women ( $n=75$ ) who did not receive the full intervention and were thus also excluded from the analysis. Thus a significant bias may have occurred with the $27.1 \%$ (or $38 \%$ ) of women who were reported as dropping out, and what was a non-significant difference in outcomes between the two groups may have become significant. 2) The Carroll 2005 study limited their analysis to providers and patients who completed the study, although they also performed a sensitivity analysis by intention to treat (i.e. administer the ALPHA) to account for those providers and patients who had dropped out. Small numbers limited the strength of the analysis and provider dropout may have played a factor. Thus $67 \%$ $(125 / 185)$ of providers declined to participate (and were thus not included in the study) while a further $20 \%$ of those remaining in the study subsequently dropped out (nine from the ALPHA group and three from the control group) leaving 48 providers. Of these, 21 providers were randomly assigned to the intervention arm and 27 to the control group. Within the patient samples, completion was at around $82 \%$ for each group (18\% dropout altogether): thus 98/118 patients in the ALPHA intervention and 129/155 con- 
trols completed the study. There was a greater loss to follow up for both providers and patients in the intervention (ALPHA) arm of the study and this combined dropout rate of providers and participants would potentially be associated with significant outcome bias.

To obtain a balanced sample, each provider was paired to another provider by practice location, age, sex, and type of provider. Provider randomisation (i.e. randomisation of clusters) was undertaken by means of computer-generated random numbers. Pregnant participants were seen by either an "intervention" or "standard care" provider. Provider dropout was caused by exclusion on the basis of illness, maternity leave, or language barrier. Pregnant participant dropouts were due to loss to follow up or incomplete forms.

The analysis was limited to pregnant participants completing the study. A sensitivity analysis by intention to treat was done to account for the nine providers in the ALPHA group and the three providers in the control group who dropped out. Each missing provider was imputed with five patients, each with no psychosocial concerns. Hierarchical logistic regression was used to control for clustering of women per provider.

Whilst the Carroll 2005 study did not evaluate the impact of psychosocial assessment on maternal clinical outcomes either antenatally or postnatally, this was partially addressed in the secondary analysis of this study (reported in Blackmore 2006). Thus the EDS scores were examined in the ALPHA group both antenatally and at approximately six weeks postpartum (a score of greater than nine indicating vulnerability to depression). The fact that the authors did not also report the mean postpartum EDS scores in the control group meant that we were unable to gauge whether there may have been a trend towards significance on the postnatal EDS when it was quantified as a continuous variable.

\section{Effects of interventions}

\section{Screening versus standard care}

\section{IDEA (Identify, Educate and Alert) versus standard care}

In Webster 2003a, the two groups of women were comparable on obstetric and psychosocial risk factors, as well as referral for social work or psychiatric assessment. There were no significant differences in EPDS scores greater than 12 at 16 weeks postpartum between the intervention group and the standard care group (RR $0.86,95 \%$ CI 0.61 to $1.21 ; 371$ women). The results did not change substantially when calculated on the basis of all women randomised $(n=600)$ instead of only those available for analysis.

\section{ALPHA (Antenatal Psychosocial Health Assessment) versus standard care}

In the Carroll 2005 study, the two groups were well matched on sociodemographic factors. After adjustment for clustering and converting to relative risk (from odds ratio), there was a nonsignificant trend towards more "high level" psychosocial concerns (see
Analysis 2.1) being identified in women in the intervention group than for women in the standard care group (RR 4.61; 95\% CI 0.99 to 21.39 ). Family violence was the single factor more likely to be identified by ALPHA than through standard care. For identification of "any level" of psychosocial concern in women (see Analysis 2.2), the relative risk was 1.32 (95\% CI 0.82 to 2.11 ), which is not a statistically significant difference. When analysed by provider (see Analysis 2.3), there were also no significant differences seen between the ALPHA and the standard care groups for identification of psychosocial concerns (RR 1.05 95\% CI 0.82 to 1.35).

In Blackmore's secondary analysis of Carroll 2005, no difference between groups was seen in numbers of women with antenatal EPDS scores of more than nine identified as being of concern for depression (RR 0.69 ; $95 \%$ CI 0.35 to 1.38 , adjusted for clustering). This represents $61 \%(16 / 26)$ of women in the ALPHA group and $78 \%$ in the standard care group of women with probable depression who were not identified, indicating a failure of the ALPHA tool to identify concern about depression. As would be expected, there was a statistically significant positive correlation between the number of antenatal concerns rated on the ALPHA and the EDS score postpartum $(r=0.226 ; \mathrm{P}=0.015)$. Unlike the Webster 2003a study, the impact of administering the ALPHA could not be assessed as an intervention in its own right in terms of postnatal EDS scores, as they only seemed to measure the postnatal EDS in the ALPHA and not the control group.

\section{DISCUSSION}

This systematic review found two RCTs examining the benefits of antenatal psychosocial assessment, either on patient postnatal EDS scores or on clinician awareness and detection of probable antenatal depression. Both studies had significant methodological limitations. In particular, participant dropout rates were high and one of the studies failed to take account of the effect of clustering.

Re-analysis led to nonsignificant findings in both studies. While there was a trend to improved detection of "high level" risk factors using the ALPHA psychosocial assessment tool, the high dropout rate of the healthcare providers and selection bias in the participants makes it possible that even these results were spuriously inflated in favour of better detection of psychosocial risk.

The primary focus of the Carroll 2005 study was on healthcare providers i.e. comparing their awareness of psychosocial issues in pregnant patients after administering the antenatal ALPHA (intervention) compared to the control providers, with the secondary analysis going on to explore the impact of the use of the ALPHA on the clinicians' ability to more specifically detect probable antenatal depression. The Webster 2003a study came nearest to our review aims and evaluated the impact of an antenatal psychosocial intervention (comprising assessment with the EDS, provision of a 
postnatal depression information booklet and communication of likely risk of postnatal depression with both the relevant healthcare providers and the participants) on postnatal EDS scores at four months postpartum. Their methodology however was substantially weakened by the fact that the study was conducted in an already preselected "high risk" sample identified by the presence of at least one psychosocial risk factor (thus the whole sample had already received a "psychosocial assessment intervention" with one group then being randomised to a further educational type of "intervention" focussing on administration of the EDS).

RCTs assessing the efficacy of these types of "interventions" where there are so many confounders (including the development of new risk factors or the uptake of a psychological or pharmaceutical intervention as part of routine clinical practice) are time consuming and difficult to implement as they require follow up of very large numbers (at least several hundred) of women postpartum.

Implications of the current review for clinical and public health practice are limited at this time. We would propose a number of criteria for inclusion of future studies that should be incorporated with the methods of the next update of this review.

a) A $75 \%$ or greater participant follow-up rate would be preferable based on the follow-up rates that are reported in the Webster 2003a and Carroll 2005 studies. In addition, we would suggest that a sensitivity analysis be conducted on losses to follow up thereby, allowing use of all data and explanation of the effect, if any, of losses on the outcomes of interest.

b) Such studies should also aim to reduce bias by inclusion of blinding of detection of psychological symptoms or psychiatric diagnosis perinatally, by means of an independent assessor blind to the randomisation category or prenatal psychosocial evaluation outcome.

c) Such studies would need to clearly enunciate what referral mechanisms had been offered and what proportion of these had been taken up, in considering maternal mental health outcomes.

d) Use of an antenatal sample that has not been prescreened in anyway.

Finally, while we acknowledge that psychosocial assessment needs to be conducted in combination with referral for preventative, early intervention and treatment programs to fully impact on outcomes, this review does not examine the confounding effect of referral pathways and uptake on clinical outcomes. This should however be the aim of a future expanded or updated review as the literature in this field develops.

\section{AUTHORS'CONCLUSIONS}

\section{Implications for practice}

On the basis of the findings of this review, we are unable to comment on the efficacy of antenatal psychosocial assessment in the public health context. However, the trend towards raised level of clinician awareness for "high level" risk factors in the Carroll 2005 study provides preliminary indication of its value in the clinical setting. Implicit in both studies included in this review was the value of undertaking the assessment intervention by means of concurrent identification of risk (e.g. ALPHA) and symptom profiles (e.g. EDS) thereby identifying both at-risk and symptomatic women in pregnancy.

\section{Implications for research}

Recruitment of an adequate study population for investigation would be aided by means of a multi-centre RCT. Given the potential for confounding between the psychosocial assessment "intervention" and the more traditionally understood psychological interventions (individual or group), it will be particularly important for such studies to clearly delineate what, if any, referral mechanisms have been evaluated in terms of type and proportion of uptake, when considering outcomes. Studies that evaluate psychosocial risk and presence of depressive symptoms either antenatally or early postnatally will be useful in allowing evaluation of psychosocial outcomes by the end of the first year postpartum.

\section{ACKNOWLEDGEMENTS}

Philippa Middleton for undertaking the statistical analyses and providing essential feedback on methodological and results sections.

Nicole Reilly for her careful editing.

Lynn Hampson for providing the search.

Sonja Henderson for technical support.

As part of the pre-publication editorial process, this review has been commented on by three peers (an editor and two referees who are external to the editorial team), a member of the Pregnancy and Childbirth Group's international panel of consumers and the Group's Statistical Adviser. 


\section{R E F E R E N C E S}

\section{References to studies included in this review}

Carroll 2005 \{published data only\}

Blackmore ER, Carroll J, Reid A, Biringer A, Glazier RH, Midmer $\mathrm{D}$, et al.The use of the antenatal psychosocial health assessment (ALPHA) tool in the detection of psychosocial risk factors. Journal of Obstetrics and Gynaecology Canada 2006;28:873-8.

* Carroll JC, Reid AJ, Biringer A, Midmer D, Glazier RH, Wilson L, et al.Effectiveness of the Antenatal Psychosocial Health Assessment (ALPHA) form in detecting psychosocial concerns: a randomised controlled trial. Canadian Medical Association Journal 2005;173(3): 253-9.

Webster 2003a \{published data only\}

Webster J, Linnane J, Roberst J, Starrenburg S, Hinson J, Dibley L. IDentify, Educate and Alert (IDEA) trial: an intervention to reduce postnatal depression. British Journal of Obstetrics and Gynaecology 2003;110:842-6.

\section{References to studies excluded from this review}

Appleby 1994 \{published data only\}

Appleby L, Gregoire A, Platz C, Prince M, Kumar R. Screening women for high risk of postnatal depression. Journal of Psychosomatic Research 1994;38:539-45.

Areias 1996 \{published data only\}

Areias MEG, Kumar R, Barros H, Figueiredo E. Correlates of depression in mothers and fathers. British Journal of Psychiatry 1996; 169:36-41.

Austin 2005a \{published data only\}

Austin MP, Hadzi-Pavlovic D, Leader L, Saint K, Parker G. Antenatal screening for the prediction of postnatal depression: validation of a psychosocial pregnancy risk questionnaire. Acta Psychiatrica Scandinavica 2005;112:310-7.

Austin 2008 \{published data only\}

Austin MP, Frilingos M, Lumley J, Hadzi-Pavlovic D, Roncolato W, Acland S, et al.Brief antenatal cognitive behaviour therapy group intervention for the prevention of postnatal depression and anxiety: a randomised controlled trial. Journal of Affective Disorders 2008;105 (1-3):35-44

Brugha 2000 \{published data only\}

Brugha TS, Wheatley S, Taub NA, Culverwell A, Friedman T, Kirwan $\mathrm{P}$, et al.Pragmatic randomised trial of antenatal intervention to prevent postnatal depression by reducing psychosocial risk factors. Psychological Medicine 2000;30:1273-81.

Buist 1999 \{published data only\} Buist A, Westley D, Hill C. Antenatal prevention of postnatal depression. Archives of Women's Mental Health 1999;1(4):167-73.

Cooper 1996a \{published data only\}

Cooper PJ, Murray L, Hooper R, West A. The development and validation of a predictive index for postpartum depression. Psychological Medicine 1996;36:627-34.

Fergerson 2002 \{published data only\}

Fergerson SS, Jamieson DJ, Lindsay M. Diagnosing postpartum depression: can we do better?. American Journal of Obstetrics and Gynecology 2002;186:899-902.
Forman 1998 \{published data only\} Forman DN, Videbech P, Hedegaard M, Salvig JD, Secher NJ. Postpartum depression: identification of women at risk. British Journal of Obstetrics and Gynaecology 2000;107:1210-7.

Glasser 1998 \{published data only\} Glasser S, Barell V, Shoham A, Ziv A, Boyko V, Lusky A, et al.Prospective study of postpartum depression in an Israeli cohort: prevalence, incidence and demographic risk factors. Journal of Psychosomatic Obstetrics and Gynecology 1998;19:155-64.

Green 1994 \{published data only\} Green JM, Murray D. The use of the Edinburgh Postnatal Depression Scale in research to explore the relationship between antenatal and postnatal dysphoria. In: Cox J, Holden J editor(s). Perinatal psychiatry. London: Gaskell, 1994:180-98.

Hobfoil 1995 \{published data only\} Hobfoil SE, Ritter C, Lavin J, Hulsizer MR. Depression prevalence and incidence among inner-city pregnant and postpartum women. Journal of Consulting and Clinical Psychology 1995;63:445-53.

Honey 2003 \{published data only\} Honey KL, Bennett P, Morgan M. Predicting postnatal depression. Journal of Affective Disorders 2003;76:201-10.

Johanson 2000 \{published data only\} Johanson R, Chapman G, Murray D, Johnson I, Cox J. The North Staffordshire Maternity Hospital prospective study of pregnancy-associated depression. Journal of Psychosomatic Obstetrics and Gynecology 2000;21:93-7.

Josefsson 2001 \{published data only\} Josefsson A, Berg G, Nordin C, Sydsjo G. Prevalence of depressive symptoms in late pregnancy and postpartum. Acta Obstetricia et Gynecologica Scandinavica 2001;80:251-5.

Leverton 1989 \{published data only\}

Leverton TJ, Elliott SA. Transition to parenthood groups: a preventive intervention for perinatal depression?. In: Van Hall EV, Everard W editor(s). The free woman: women's health in the 1990s. Invited papers of the 9 th international conference of psychosomatic obstetrics and gynecology. Lancaster: Parthenon Press, 1989:479-86.

Midmer 2004 \{published data only\}

Midmer D, Bryanton J, Brown R. Assessing antenatal psychosocial health, Randomized controlled trial of two versions of the alpha form. Canadian Family Physician 2004;50:80-7.

Posner 1997 \{published data only\}

Posner NA, Unterman RR, Williams KN, Williams GH. Screening for postpartum depression: an antepartum questionnaire. Journal of Reproductive Medicine 1997;42:207-15.

Stamp 1996 \{published data only\} Stamp GE, Williams AS, Crowther CA. Predicting postnatal depression among pregnant women. Birth 1996;23:218-23.

Webster 2000 \{published data only\} Webster J, Linnane JWJ, Dibley LM, Pritchard M. Improving antenatal recognition of women at risk for postnatal depression. Australian and New Zealand Journal of Obstetrics and Gynaecology 2000; 10:409-12. 
Webster 2003b \{published data only\}

Webster J, Pritchard MA, Creedy D, East C. A simplified predictive index for the detection of women at risk for postnatal depression. Birth 2003;30:101-8.

Webster 2006 \{published data only\}

Webster J, Hall L, Somville T, Schneider P, Turnbull R, Smith P. Prospective testing of the Brisbane Postnatal Depression Index. Birth 2006;33:56-63.

Zlotnick 2001 \{published data only\}

Zlotnick C, Johnson SL, Miller I, Pearlstein T, Howard M. Postpartum depression in women receiving public assistance: pilot study of an inter-personal-therapy oriented group program. American Journal of Psychiatry 2001;158:638-40.

\section{Additional references}

\section{APA 1994}

American Psychiatric Association. Diagnostic and statistical manual of mental disorders. Washington: American Psychiatric Association, 1994.

Appleby 1997

Appleby L, Warner R, Whitton A, Faragher BA. A controlled study of fluoxetine and cognitive-behavioural counselling in the treatment of postnatal depression. BMJ 1997;314:932-6.

\section{Atkinson 1997}

Atkinson L, Zucker KJ. Attachment and psychopathology. NY: Guilford Press, 1997.

\section{Austin 2000}

Austin MP, Leader L. Maternal stress and obstetric and infant outcomes: epidemiological findings and neuroendocrine mechanisms. Australian and New Zealand Journal of Obstetrics and Gynaecology 2000;40:331-7.

\section{Austin 2003a}

Austin MP, Lumley J. Antenatal screening for postnatal depression: a systematic review. Acta Psychiatrica Scandinavica 2003;107(1):10-7.

\section{Austin 2003b}

Austin MP. Psychosocial assessment and management of depression and anxiety in pregnancy. Australian Family Physician 2003;32(3): $119-26$.

\section{Austin 2003c}

Austin MP. Targeted group antenatal prevention of postnatal depression: a review. Acta Psychiatrica Scandinavica. 2003;107(4):244-50.

Austin 2005

Austin M-P, Hadzi-Pavlovic D, Leader L, Saint K, Parker G. Antenatal screening for the prediction of postnatal depression: validation of a psychosocial pregnancy risk questionnaire. Acta Psychiatrica Scandinavica 2005;112:310-7.

\section{Austin 2007}

Austin M-P, Kildea S, Sullivan E. Perinatal maternal mortality and psychiatric morbidity: challenges and opportunities for prevention in the Australian setting. Medical Journal of Australia 2007;186(7): $364-7$.

\section{Bacchus 2004}

Bacchus L, Mezey G, Bewley S. Domestic violence: prevalence in pregnant women and associations with physical and psychological health. European Journal of Obstetrics \& Gynecology and Reproductive Biology 2004;113(1):6-11.

\section{Barlow 2003}

Barlow J, Coren E. Parent-training programmes for improving maternal psychosocial health. The Cochrane Database of Systematic Reviews 2003, Issue 4. Art. No.: CD002020.pub2. DOI: 10.1002/14651858.CD002020.pub2.

\section{Barnett 1993}

Barnett B, Lockhart K, Bernard D, Maricavasagar V, Dudley M. Mood disorders among infants of mothers admitted to a mothercraft hospital. Journal of Paediatrics and Child Health 1993;29:270-5.

\section{Barnett 2005}

Barnett B, Glossop P, Matthey S, Stewart H. Screening in the context of Integrated Perinatal Care. In: Henshaw C, Elliott S editor(s). Screening for Perinatal Depression. London: Jessica Kingsley, 2005.

Beck 1961

Beck AT, Ward CH, Mendelson M. An inventory for measuring depression. Archives of General Psychiatry 1961;4:561-71.

\section{Blackmore 2006}

Blackmore ER, Carroll J, Reid A, Biringer A, Glazier RH, Midmer $\mathrm{D}$, et al.The use of the antenatal psychosocial health assessment (ALPHA) tool in the detection of psychosocial risk factors. Journal of Obstetrics and Gynaecology Canada 2006;28:873-8.

\section{Boyce 1994}

Boyce P. Personality dysfunction, marital problems, and postnatal depression. In: Cox J, Holden J editor(s). Use and misuse of the Edinburgh Postnatal Depression Scale. London: Gaskell, 1994.

\section{Brockington 2004}

Brockington I. Postpartum psychiatric disorders. Lancet 2004;363: 303-10.

\section{Buist 2002}

Buist AE, Barnett BE, Milgrom J, Pope S, Condon JT, Ellwood D, et al.To screen or not to screen--that is the question in perinatal depression. Medical Journal of Australia 2002;177 Suppl:S101-5.

\section{Buist 2006}

Buist A, Condon J, Brooks J, Speelman C, Milgrom J, Hayes B, et al.Acceptability of routine screening for postnatal depression. Journal of Affective Disorders 2006;93:233-7.

\section{Campbell 1995}

Campbell S, Cohn J, Meyers T. Depression in first-time mothers: mother-infant interaction, and depression chronicity. Developmental Psychology 1995;31:349-57.

\section{Carter 2003}

Carter AS, Garrity-Roukas FE, Chazan-Cohen R, Little C, BroggsGowan M. Maternal depression and co-morbidity: predicting early parenting, attachment security and toddler social-emotional problems and competencies. Journal of the American Academy of Child and Adolescent Psychiatry 2003;40:18-26.

\section{Civic 1993}

Civic D, Holt VL. Maternal depressive symptoms and child behaviour problems in a nationally representative normal birthweight sample. Maternal and Child Health 1993;29:270-5. 


\section{Cooper 1995}

Cooper PJ, Murray L. Course and recurrence of postnatal depression: evidence for the specificity of the diagnostic concept. British Journal of Psychiatry 1995;166:191-5.

Cooper 2003

Cooper PJ, Murray L, Wilson A, Romaniuk H. Controlled trial of the short- and long-term effect of psychological treatment of postpartum depression. Impact on maternal mood. British Journal of Psychiatry 2003;182:412-9.

Cox 1987

Cox JL, Holden JM, Sagovsky R. Detection of postnatal depression. British Journal of Psychiatry 1987;150:782-6.

\section{Cox 1993}

Cox J, Murray D, Chapman G. A controlled study of the onset, duration and prevalence of postnatal depression. British Journal of Psychiatry 1993;163:27-31.

\section{Dennis 1999}

Dennis CL, Ross LE, Herxheimer A. Oestrogens and progestins for preventing and treating postpartum depression. Cochrane Database of Systematic Reviews 1999, Issue 3.[Art. No.: CD001690. DOI: 10.1002/14651858.CD001690.pub2]

\section{Dennis 2004}

Dennis C-L, Creedy D. Psychosocial and psychological interventions for preventing postpartum depression. Cochrane Database of Systematic Reviews 2004, Issue 4. [Art. No.: CD001134. DOI: 10.1002/14651858.CD001134.pub2]

\section{Doggett 2005}

Doggett C, Burrett S, Osborn DA. Home visits during pregnancy and after birth for women with an alcohol or drug problem. Cochrane Database of Systematic Reviews 2005, Issue 4. [Art. No.: CD004456. DOI: 10.1002/14651858.CD004456.pub2]

Elliot 2000

Elliot SA, Leverton TJ, Sanjack M, Turner H, Cowmeadow P, Hopkins J, et al.Promoting mental health after childbirth: a controlled trial of primary prevention of postnatal depression. British Journal of Clinical Psychology 2000;39:223-1.

\section{Endicott 1978}

Endicott J, Spitzer R. A diagnostic interview: the schedule for affective disorders and schizophrenia. Archives of General Psychiatry 1978; 35:837-44.

\section{Fergusson 1996}

Fergusson DM, Horwood LJ, Thorpe K. Changes in depression during and following pregnancy. ALSPAC Study Team. Study of pregnancy and children. Perinatal Epidemiology 1996;10:279-93.

Gavin 2005

Gavin NI, Gaynes BN, Lohr KN, Meltzer-Brody S, Gatrlehner G, Swinson T. Perinatal depression: a systematic review of prevalence and incidence. Obstetrics and Gynecology 2005;106:1071-83.

\section{Glover 2002}

Glover V, O'Connor TG. Effects of antenatal stress and anxiety. British Journal of Psychiatry 2002;180:389-91.

\section{Gotzsche 2006}

Gotzsche PC, Nielsen M. Screening for breast cancer with mammography. Cochrane Database of Systematic Reviews 2006, Issue 4. [Art. No.: CD001877. DOI: 10.1002/14651858.CD001877.pub2]

\section{Heron 2004}

Heron J, O'Connor TG, Evans J, Golding J, Glover V. The course of anxiety and depression through pregnancy and the postpartum in a community sample. Journal of Affective Disorders 2004;80:65-73.

\section{Higgins 2008}

Higgins JPT, Green S, editors. Cochrane Handbook for Systematic Reviews of Interventions 5.0.0 [updated February 2008]. The Cochrane Collaboration, 2008.

\section{Hoffbrand 2001}

Hoffbrand S, Howard L, Crawley H. Antidepressant treatment for post-natal depression. Cochrane Database of Systematic Reviews 2001, Issue 2. [Art. No.: CD002018. DOI: 10.1002/14651858.CD002018]

\section{Howard 2005}

Howard LM, Hoffbrand S, Henshaw C, Boath L, Bradley E. Antidepressant prevention of postnatal depression. Cochrane Database of Systematic Reviews 2005, Issue 2. [Art. No.: CD004363. DOI: 10.1002/14651858.CD004363.pub2]

\section{Huizink 2002}

Huizink AC, Robles De Medina PG, Mulder EJH, Visser GHA. Psychological measures of prenatal stress as predictors of infant temperament. Journal of the American Academy of Child and Adolescent Psychiatry 2002;41(9):1078-85.

\section{Lumley 2004}

Lumley J, Austin MP, Mitchell C. Intervening to reduce depression after birth: a systematic review of the randomized trials. International Journal of Technology and Assessment in Health Care 2004;20(2):12844.

Matthey 2003

Matthey S, Barnett B, Howie P, Kavanagh DJ. Diagnosing postpartum depression in mothers and fathers: whatever happened to anxiety?. Journal of Affective Disorders 2003;74:139-47.

\section{Matthey 2004}

Matthey S. Detection and treatment of postnatal depression or anxiety. Current Opinion in Psychiatry 2004;17(1):21-9.

\section{McNair 1971}

McNair DM, Lorr M, Droppleman LF. Profile of mood states. San Diego, CA: Educational and Industrial Testing Service, 1977.

\section{Mietinnen 2003}

Miettinnen OS, Yankelevitz DF, Henschke CI. Evaluation of screening for a cancer: annotated catechism of the Gold Standard creed. Journal of Evaluation of Clinical Practice 2003;9:145-50.

\section{Misri 2000}

Misri S, Kostaras X, Fox D, Kostaras D. The impact of partner support in the treatment of postpartum depression. Canadian Journal of Psychiatry 2000;45:554-8.

\section{Murray 1990}

Murray D, Cox JL. Screening for depression during pregnancy with the Edinburgh Postnatal Depression Scale. Journal of Reproductive and Infant Psychology 1990;8:99-107.

\section{Murray 1997}

Murray L, Cooper P. Postpartum depression and child development. Psychological Medicine 1997;27:253-60. 


\section{Murray 2003}

Murray L, Woolgar M, Murray J, Cooper P. Self-exclusion from health care in women at high risk for postpartum depression. Journal of Public Health Medicine 2003;25(2):131-7.

\section{Murray 2004}

Murray L, Cooper PJ. The impact of postnatal depression on child development. In: Goodyer I editor(s). Aetiologicalmechanisms in developmental psychopathology. Oxford: Oxford University Press, 2004.

\section{NICE 2007}

National Institute of Clinical Excellence (UK). Antenatal and postnatal mental health: clinical management and service guidance. http: www.nice.org.uk/CG45 2007.

\section{NSC 1998}

National Screening Committee. Health Departments of the United Kingdom. Criteria for appraising the viability,effectiveness and appropriateness of a screening programme. In: First Report of the $\mathrm{Na}$ tional Screening Committee. Oxford: Health Departments of the United Kingdom, 1998.

\section{NSC 2003}

National Electronic Library for Screening. Depression: National Screening Committee Policy Position. http://www.nelh.nhs.uk/screening/adult_pps/depression.html (accessed March 2003).

\section{O'Connor 2002}

O'Connor TG, Heron J, Golding J, Beveridge M, Glover V. Maternal antenatal anxiety and children's behavioural/emotional problems at 4 years: report from the ALSPAC. British Journal of Psychiatry 2002; 180:502-8.

\section{O’Hara 1997}

O'Hara M. The nature of postpartum depressive disorders. In: Murray $\mathrm{L}$, Cooper $\mathrm{P}$ editor(s). Postpartum depression and child development. New York: Guilford, 1997.

\section{O'Hara 2004}

O'Hara MW, Gorman LL. Can postpartum depression be predicted?. Primary Psychiatry 2004;11(3):42-7.

\section{Oates 2003}

Oates M. Perinatal psychiatric disorders: a leading cause of maternal morbidity and mortality. British Medical Bulletin 2003;67:219-29.

\section{Ogrodniczuk 2003}

Ogrodniczuk JS, Piper WE. Preventing postnatal depression: a review of research findings. Harvard Review of Psychiatry 2003;11(6): 291-307.

\section{Patel 2004}

Patel V, Rahman A, Jacob KS, Hughes M. Effect of maternal health on infant growth in low income countries: new evidence from South Asia. BMJ 2004;328:820-3.

\section{Preisig 2001}

Preisig M, Merikangas KR, Angst J. Clinical significance and comorbidity of subthreshold depression and anxiety in the community. Acta Psychiatrica Scandinavica 2001;104:96-103.

\section{Priest 2003}

Priest SR, Henderson J, Evans SF, Hagan R. Stress debriefing after childbirth: a randomised controlled trial. Medical Journal of Australia 2003; 178:542-5.

\section{Radloff 1977}

Radloff LS. The CES-D Scale: a self-report depression scale for research in the general population. Applied Psychological Measurement 1977;1:385-401.

\section{RevMan 2008}

The Nordic Cochrane Centre. Review Manager (RevMan). 5.0 for Windows. Copenhagen: The Nordic Cochrane Centre, 2008.

\section{Robins 1981}

Robins LN, Helzer JE, Croughan J. National Institute of Mental Health Diagnostic Interview Schedule: its history, characteristics and validity. Archives of General Psychiatry 1981;38:381-91.

\section{Shakespeare 2001}

Shakespeare J. Evaluation of
screening for postnatal depression against the NSC handbook criteria. http://www.nelh.nhs.uk/screening/adult_pps/Shakespeare_final paper.pdf (accessed June 2001).

\section{Sheehan 1998}

Sheehan DV, Lecrubier Y, Sheehan KH, Amorim P, Janavs J, Weiller E, et al.The Mini-International Neuropsychiatric Interview (M.I.N.I): the development and validation of a structured diagnostic psychiatric interview for DSM-IV and ICD-10. Journal of Clinical Psychiatry 1998;59 Suppl 20:22-33.

\section{Spielberger 1970}

Spielberger CD, Gorsuch RL, Lushene RE. Manual for the StateTrait Anxiety Inventory (Self evaluation questionnaire). Palo Alto, CA: Consulting Psychologists Press, 1970.

\section{Stuart 1998}

Stuart S, Couser G, Schilder K, O’Hara M, Gorman L. Postpartum anxiety and depression: onset and comorbidity in a community sample. Journal of Nervous and Mental Disorders 1998;186:420-4.

\section{Verkerk 2003}

Verkerk GJM, Pop VJM, Van Son MJM, Van Heck GL. Prediction of depression in the postpartum period: a longitudinal follow-up study in high-risk and low-risk women. Journal of Affective Disorders 2003;77:159-66.

* Indicates the major publication for the study 


\section{CHARACTERISTICS OFSTUDIES}

\section{Characteristics of included studies [ordered by study ID]}

\section{Carroll 2005}

\begin{tabular}{|c|c|}
\hline Methods & $\begin{array}{l}\text { Randomisation performed by biostatistician using computer generated random numbers. Providers in the } \\
\text { intervention group attended a training session on the use of the ALPHA questionnaire. Control group } \\
\text { provided usual care. Women were seen once in pregnancy and reviewed at } 1 \text { month postpartum. } \\
\text { As per the primary study described in Carroll 2005, in addition the EDS was also administered at } 6 \text { weeks } \\
\text { postpartum to identify women with postpartum depression. }\end{array}$ \\
\hline Participants & $\begin{array}{l}21 \text { providers (midwives, obstetricians, and family physicians) assigned to the ALPHA condition and } 27 \\
\text { assigned to the control condition. Providers saw } 227 \text { pregnant women (98 ALPHA group, } 129 \text { control) } \\
\text { between } 12-30 \text { weeks' gestation. } \\
98 \text { women receiving the ALPHA psychosocial questionnaire; } 129 \text { controls. }\end{array}$ \\
\hline Interventions & $\begin{array}{l}\text { The ALPHA, a psychosocial health assessment questionnaire, given antenatally; the control group received } \\
\text { usual antenatal care. }\end{array}$ \\
\hline Outcomes & $\begin{array}{l}\text { The study compared the capacity of ALPHA group providers vs. control providers in identifying psy- } \\
\text { chosocial risk factors. A secondary aim was to examine the relationship between the presence and number } \\
\text { of antenatal risk factors and a postnatal EPDS score }>9 \text {. }\end{array}$ \\
\hline Notes & $\begin{array}{l}\text { Bias may have occurred with greater ALPHA than control provider dropout. } 72.7 \% \text { women comfortable } \\
\text { with discussing psychosocial issues; } 64 \% \text { of those providers responding found the ALPHA easy to use and } \\
86 \% \text { would use it routinely if it was recommended. } \\
\text { This review undertook re-analysis of the data and reported an OR of } 1.64 \text { (vs. OR } 1.8 \text { reported by authors } \\
\text { in published article). } \\
\text { Blackmore } 2006 \text { performed a secondary analysis of the Carroll } 2005 \text { data focusing on postpartum outcome } \\
\text { as a function of the administration of the ALPHA antenatally. }\end{array}$ \\
\hline
\end{tabular}

\section{Risk of bias}

\begin{tabular}{lll}
\hline Item & Authors' judgement & Description \\
\hline Allocation concealment? & Yes & A - Adequate
\end{tabular}


Webster 2003a

\begin{tabular}{|c|c|c|}
\hline Methods & \multicolumn{2}{|c|}{$\begin{array}{l}2199 \text { women identified as at risk and thus eligible for the study on the presence of one of } 5 \text { psychosocial } \\
\text { risk factors. } 1599 \text { women excluded primarily on absence of such risk factors or refusing consent }(\mathrm{N}= \\
\text { 91) or not meeting inclusion criteria or missed }(\mathrm{N}=52+29) \text {. Randomisation of remaining } 600 \text { women } \\
\text { using computer-generated list of random numbers. Participants reviewed at } 4 \text { months postpartum with } \\
\text { an EDS. }\end{array}$} \\
\hline Participants & \multicolumn{2}{|c|}{299 women randomised to the intervention; 301 controls. } \\
\hline Interventions & \multicolumn{2}{|c|}{$\begin{array}{l}\text { Consisting of an Edinburgh Depression Scale and a discussion of their likely risk of PND based on their } \\
\text { EDS score, an information booklet about postnatal depression and available local resources, and a letter } \\
\text { was sent back to the referring GP and Child Health Nurse advising of their likely risk of PND. The } \\
\text { control group received usual antenatal care. }\end{array}$} \\
\hline Outcomes & \multicolumn{2}{|c|}{$\begin{array}{l}\text { The study reported on obstetric and psychosocial risk factors, as well as referral to social work or psychiatry } \\
\text { and examined EPDS scores at } 16 \text { weeks postnatally. }\end{array}$} \\
\hline Notes & \multicolumn{2}{|c|}{$\begin{array}{l}\text { Bias may have occurred with the } 27.1 \% \text { women who were reported as dropping out. The rate of dropout } \\
\text { was } 38 \% \text { if we include those women }(\mathrm{N}=75) \text { who did not receive the full intervention and were thus } \\
\text { also excluded from the analysis. Thus what was a non-significant difference between the two groups may } \\
\text { have become significant. The authors did not allow us to gauge the differences between the two groups } \\
\text { in EDS scores postpartum; thus we were unable to gauge whether there may have been a trend towards } \\
\text { significance on the EDS when it was quantified as a continuous variable. }\end{array}$} \\
\hline \multicolumn{3}{|l|}{ Risk of bias } \\
\hline Item & Authors' judgement & Description \\
\hline Allocation concealment? & Yes & A - Adequate \\
\hline
\end{tabular}

Characteristics of excluded studies [ordered by study ID]

\begin{tabular}{ll}
\hline Appleby 1994 & Not a RCT. \\
\hline Areias 1996 & Not a RCT. \\
\hline Austin 2005a & Not a RCT. \\
\hline Austin 2008 & RCT for allocation to antenatal group intervention not for psychosocial assessment. \\
\hline Brugha 2000 & RCT for allocation to antenatal group intervention not for psychosocial assessment.
\end{tabular}

Antenatal psychosocial assessment for reducing perinatal mental health morbidity (Review) 
(Continued)

\begin{tabular}{|c|c|}
\hline Buist 1999 & Not a RCT. \\
\hline Cooper 1996a & Not a RCT. \\
\hline Fergerson 2002 & Not a RCT. \\
\hline Forman 1998 & Not a RCT. \\
\hline Glasser 1998 & Not a RCT. \\
\hline Green 1994 & Not a RCT. \\
\hline Hobfoil 1995 & Not a RCT. \\
\hline Honey 2003 & Not a RCT. \\
\hline Johanson 2000 & Not a RCT. \\
\hline Josefsson 2001 & Not a RCT. \\
\hline Leverton 1989 & Not a RCT. \\
\hline Midmer 2004 & Comparison of two versions of the ALPHA tool; no relevant outcomes reported. \\
\hline Posner 1997 & Not a RCT. \\
\hline Stamp 1996 & RCT for allocation to antenatal group psychosocial intervention; not for psychosocial assessment. \\
\hline Webster 2000 & Not a RCT. \\
\hline Webster 2003b & RCT for allocation to antenatal group psychosocial intervention; not for psychosocial assessment. \\
\hline Webster 2006 & Not an RCT \\
\hline Zlotnick 2001 & RCT for allocation to group psychosocial antenatal intervention; not for psychosocial assessment. \\
\hline
\end{tabular}

RCT: randomised controlled trial 
DATA AND ANALYSES

Comparison 1. IDEA versus standard care

\begin{tabular}{lcccc} 
Outcome or subgroup title & $\begin{array}{c}\text { No. of } \\
\text { studies }\end{array}$ & $\begin{array}{c}\text { No. of } \\
\text { participants }\end{array}$ & Statistical method & Effect size \\
\hline $\begin{array}{c}1 \text { EPDS }>12 \text { (at } 16 \text { weeks } \\
\text { postpartum) }\end{array}$ & 1 & 371 & Risk Ratio (M-H, Fixed, 95\% CI) & $0.86[0.61,1.21]$ \\
\hline
\end{tabular}

Comparison 2. ALPHA versus standard care

\begin{tabular}{lcccc} 
Outcome or subgroup title & $\begin{array}{c}\text { No. of } \\
\text { studies }\end{array}$ & $\begin{array}{c}\text { No. of } \\
\text { participants }\end{array}$ & Statistical method & Effect size \\
\hline $\begin{array}{l}1 \text { High level of provider concern } \\
\quad \text { (adj for cluster) }\end{array}$ & 1 & 139 & Risk Ratio (M-H, Fixed, 95\% CI) & $4.61[0.99,21.39]$ \\
$\begin{array}{l}2 \text { At least one psychosocial concern } \\
\text { identified (adj for cluster) }\end{array}$ & 1 & 139 & Risk Ratio (M-H, Fixed, 95\% CI) & $1.32[0.82,2.11]$ \\
$\begin{array}{l}3 \text { At least one concern identified } \\
\text { in at least one woman (by } \\
\text { provider) }\end{array}$ & 1 & 48 & Risk Ratio (M-H, Fixed, 95\% CI) & $1.05[0.82,1.35]$ \\
$\begin{array}{l}4 \text { Women identified with a risk } \\
\text { factor (adj for cluster) }\end{array}$ & 1 & 124 & Risk Ratio (M-H, Fixed, 95\% CI) & $1.36[0.79,2.32]$ \\
$\begin{array}{l}5 \text { Failure to identify EPDS }>9 \\
\text { antenatally }\end{array}$ & 1 & 139 & Risk Ratio (M-H, Fixed, 95\% CI) & $0.69[0.35,1.38]$ \\
\hline
\end{tabular}

\section{Analysis I.I. Comparison I IDEA versus standard care, Outcome I EPDS > I 2 (at I6 weeks postpartum).}
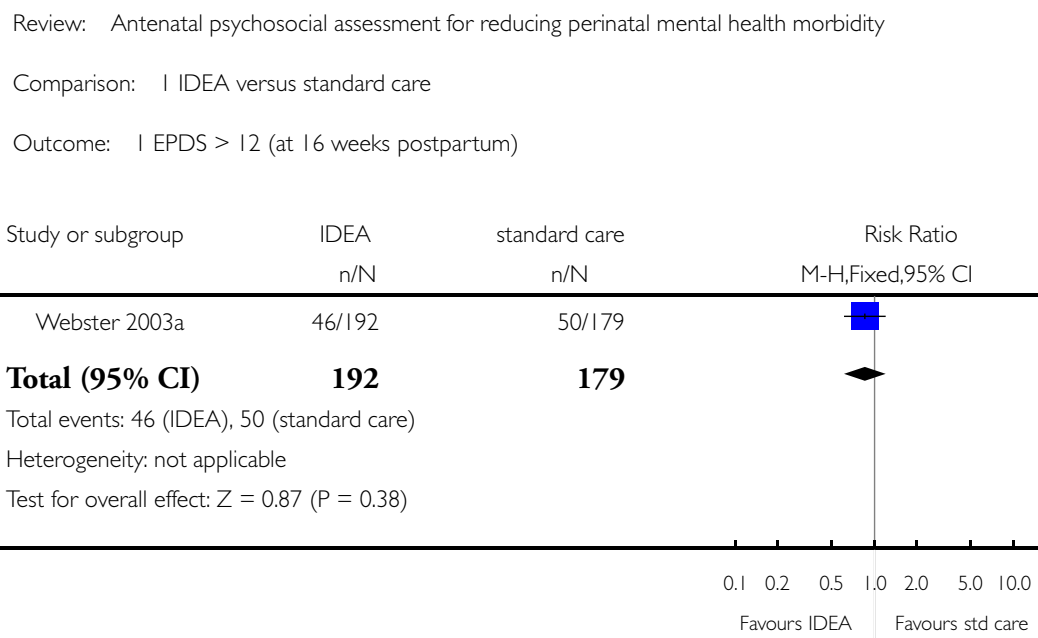
Analysis 2.I. Comparison 2 ALPHA versus standard care, Outcome I High level of provider concern (adj for cluster).

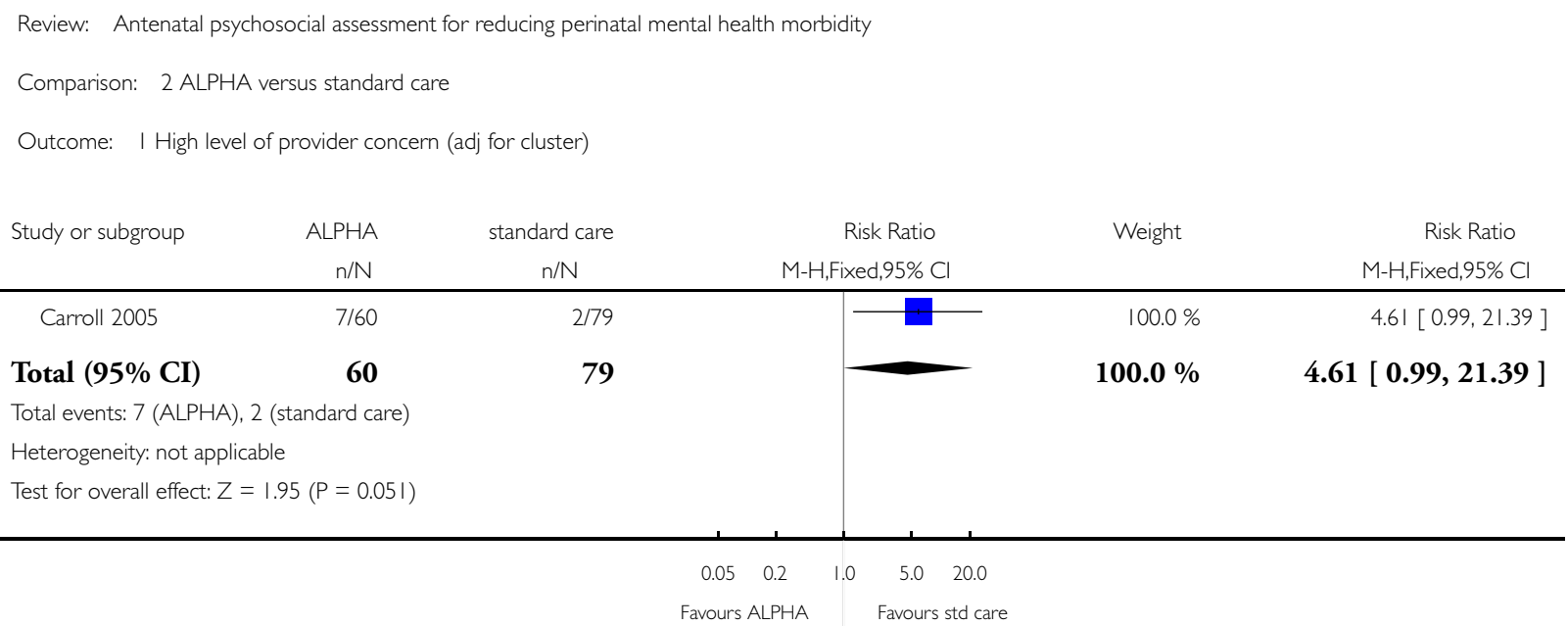

\section{Analysis 2.2. Comparison 2 ALPHA versus standard care, Outcome 2 At least one psychosocial concern} identified (adj for cluster).

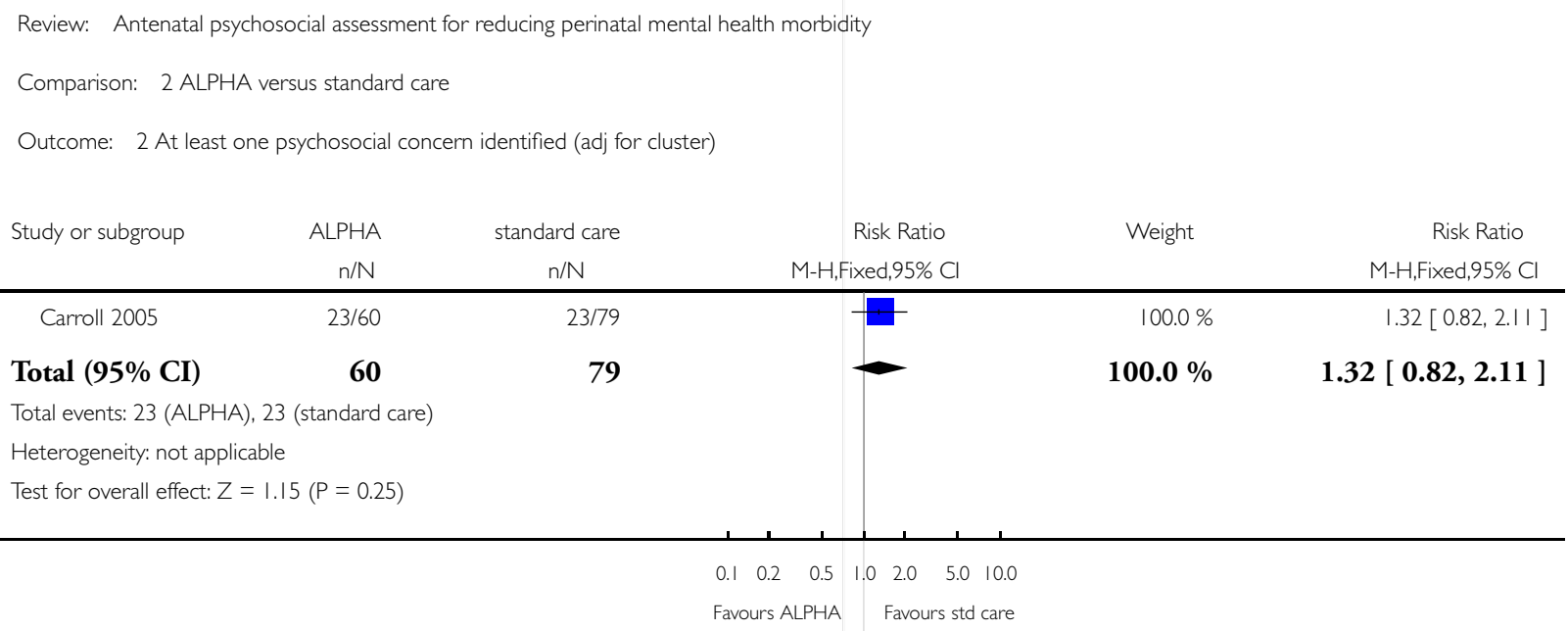


Analysis 2.3. Comparison 2 ALPHA versus standard care, Outcome 3 At least one concern identified in at least one woman (by provider).

\begin{tabular}{|c|c|c|c|c|c|}
\hline \multicolumn{6}{|c|}{ Comparison: 2 ALPHA versus standard care } \\
\hline \multicolumn{6}{|c|}{ Outcome: 3 At least one concern identified in at least one woman (by provider) } \\
\hline \multirow[t]{2}{*}{ Study or subgroup } & ALPHA & standard care & Risk Ratio & Weight & Risk Ratio \\
\hline & $\mathrm{n} / \mathrm{N}$ & $\mathrm{n} / \mathrm{N}$ & M-H,Fixed,95\% Cl & & M-H,Fixed,95\% Cl \\
\hline Carroll 2005 & $18 / 21$ & $22 / 27$ & f & $100.0 \%$ & $1.05[0.82,1.35]$ \\
\hline Total $(95 \% \mathrm{CI})$ & 21 & 27 & - & $100.0 \%$ & $1.05[0.82,1.35]$ \\
\hline \multicolumn{6}{|c|}{ Total events: 18 (ALPHA), 22 (standard care) } \\
\hline \multicolumn{6}{|c|}{ Heterogeneity: not applicable } \\
\hline \multicolumn{6}{|c|}{ Test for overall effect: $Z=0.40(P=0.69)$} \\
\hline
\end{tabular}

\section{Analysis 2.4. Comparison 2 ALPHA versus standard care, Outcome 4 Women identified with a risk factor} (adj for cluster).

\begin{tabular}{|c|c|c|c|c|c|}
\hline \multicolumn{6}{|c|}{ Comparison: 2 ALPHA versus standard care } \\
\hline \multicolumn{6}{|c|}{ Outcome: 4 Women identified with a risk factor (adj for cluster) } \\
\hline \multirow[t]{2}{*}{ Study or subgroup } & ALPHA & standard care & Risk Ratio & Weight & Risk Ratio \\
\hline & $n / N$ & $n / N$ & M-H,Fixed, $95 \% \mathrm{Cl}$ & & M-H,Fixed,95\% Cl \\
\hline Carroll 2005 & $|8 / 5|$ & $19 / 73$ & & $100.0 \%$ & $1.36[0.79,2.32]$ \\
\hline Total $(95 \% \mathrm{CI})$ & 51 & 73 & - & $100.0 \%$ & $1.36[0.79,2.32]$ \\
\hline \multicolumn{6}{|c|}{ Total events: 18 (ALPHA), 19 (standard care) } \\
\hline \multicolumn{6}{|c|}{ Heterogeneity: not applicable } \\
\hline \multicolumn{6}{|c|}{ Test for overall effect: $Z=1.11$ ( $P=0.27)$} \\
\hline
\end{tabular}




\section{Analysis 2.5. Comparison 2 ALPHA versus standard care, Outcome 5 Failure to identify EPDS > 9 antenatally.}

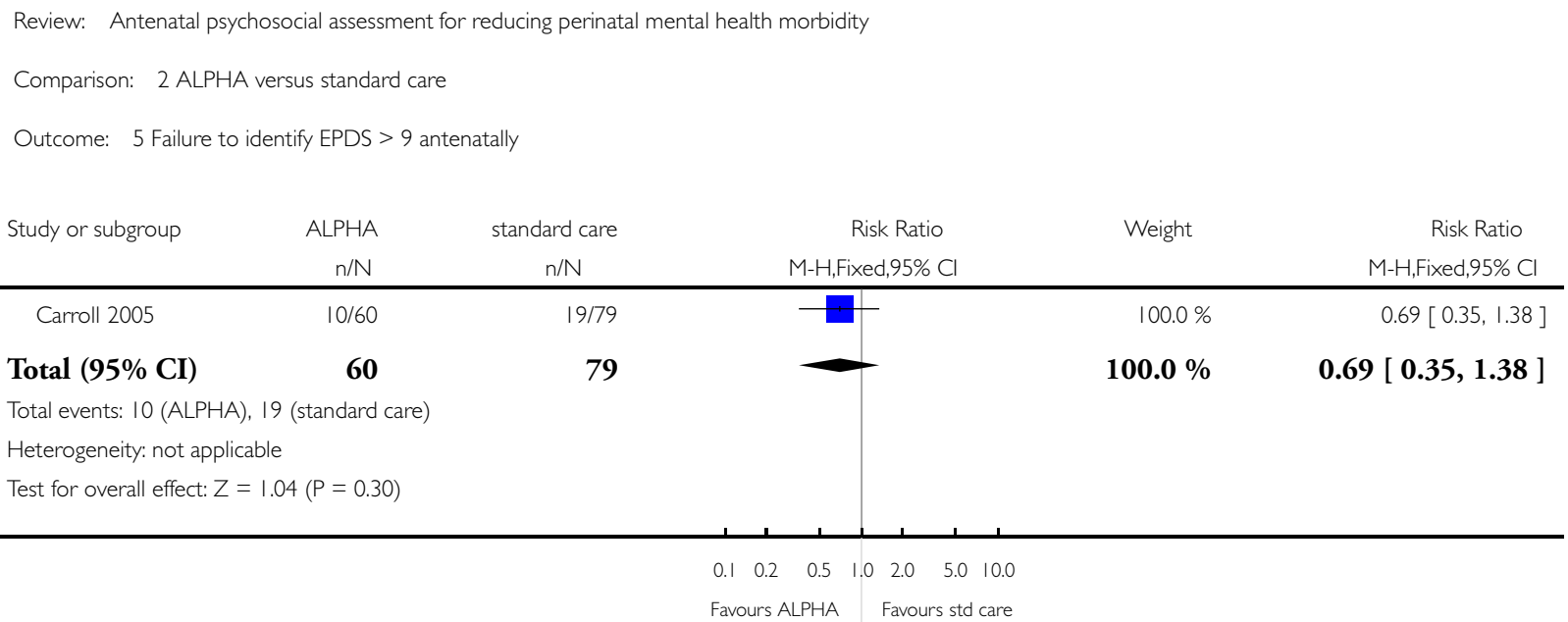

\section{WHAT'S NEW}

Last assessed as up-to-date: 6 June 2008.

24 June 2008 Amended Converted to new review format.

\section{H I S T O R Y}

Protocol first published: Issue 1, 2005

Review first published: Issue 4, 2008

\section{CONTRIBUTIONS OFAUTHORS}

Marie-Paule Austin (MPA) and Susan Priest (SP) conceived the review, and developed the protocol and search strategy.

MPA and SP screened search results against inclusion criteria.

MPA and PM did quality rating for the studies.

Philippa Middleton (PM) did data extraction and wrote the methods of the review section.

MPA and SP provided a clinical perspective.

MPA wrote the background, results, and conclusion.

ES provided a methodological perspective. 


\section{DECLARATIONSOF INTEREST}

None known.

\section{SOURCES OF SUPPORT}

\section{Internal sources}

- University of New South Wales \& Black Dog Institute, Sydney, Australia.

\section{External sources}

- No sources of support supplied

\section{DifFERENCES BETWEEN PROTOCOLANDREVIEW}

\section{Title}

We have changed the shift in emphasis from postnatal depression to perinatal mental health, and from screening to assessment. We have therefore changed the title of the review from 'Antenatal psychosocial screening for prevention of postnatal depression' to 'Antenatal psychosocial assessment for reducing perinatal mental health morbidity' to make this clear.

\section{Background}

We have updated the background to focus on the issue of terminology, distinction between screening and assessment, and the reason for choosing the latter.

\section{Objectives}

We have changed the primary aims to evaluate the effectiveness of antenatal psychosocial assessment (compared to routine antenatal care) in reducing the mental health morbidity of women during pregnancy and the postnatal period.

\section{Secondary aims}

We have changed the secondary aims from (1) review of criteria used to determine risk status, and (2) to examine the methods used to diagnose anxiety and depression to (1) to assess for adverse maternal outcomes associated with antenatal and early postnatal psychosocial screening, and (2) to provide a brief review of the screening properties of the key antenatal psychosocial screening tools developed to date. 